\title{
Mudança de larga escala na política ambiental: análise da realidade brasileira
}

\author{
Mauro Guilherme Maidana Capelari ${ }^{1}$
}

Suely Mara Vaz Guimarães de Araújo 23

Paulo Carlos Du Pin Calmon ${ }^{3}$

Benilson Borinelli ${ }^{4}$

1 Universidade de Brasília / Centro de Desenvolvimento Sustentável, Brasília / DF - Brasil

2 Universidade de Brasília / Instituto Brasiliense de Direito Público, Brasília / DF - Brasil

3 Universidade de Brasília / Instituto de Ciência Política, Brasília / DF - Brasil

${ }^{4}$ Universidade Estadual de Londrina / Departamento de Administração, Londrina / PR - Brasil

\begin{abstract}
As eleições presidenciais brasileiras de 2018 trouxeram mudanças em larga escala no subsistema de política ambiental do país. O objetivo deste artigo é analisar essas mudanças através do Advocacy Coalition Framework - ACF. Para isso, introduzimos algumas das principais características do subsistema de política ambiental e, a seguir, apresentamos uma análise hemerográfica para descrever e analisar os efeitos de quatro choques recentes no subsistema em análise. Dois desses choques foram externos: (i) a ascensão ao poder de uma nova elite política que trouxe um discurso claro de negação da relevância da política ambiental e (ii) eventos ambientais calamitosos que ocorreram no Brasil em 2019. Dois outros choques foram internos: (i) a captura de posições e recursos importantes pelos membros da coalizão dominante e (ii) o surgimento de conflitos e polarizações entre as coalizões no subsistema. Os resultados mostraram: (i) a ascensão de um subsistema hiper-contraditório; (ii) o realinhamento entre coalizões não dominantes em direção à cooperação; (iii) a imposição de barreiras claras à negociação; e (iv) mudanças no uso da informação científica por discursos mais politizados com alto grau de viés. O artigo contribui para a compreensão dos processos de mudança institucional na política ambiental, especialmente em contextos de mudança em larga escala gerados pelo aumento da polarização eleitoral e intensas disputas políticas. Contribui também para a análise dos limites e possibilidades do ACF na agenda ambiental brasileira.
\end{abstract}

Palavras-chave: política ambiental; mudança política; advocacy coalition framework; política brasileira.

\section{Cambio de gran escala en la política ambiental: análisis de la realidad brasileña}

Las elecciones presidenciales brasileñas de 2018 introdujeron cambios de gran escala en el subsistema de política ambiental del país. El propósito de este documento es analizar estos cambios a través de las lentes del Advocacy Coalition Framework - ACF. Para ello, exponemos algunas de las características principales de este subsistema y, luego, presentamos un análisis hemerográfico para describir y analizar los efectos de cuatro shocks recientes en este subsistema. Dos de estos shocks fueron externos: (i) el ascenso de una nueva élite política al poder, la cual ha traído un claro discurso de negación de la relevancia de la política ambiental y (ii) catastróficos eventos ambientales que ocurrieron en Brasil durante 2019. Otros dos shocks fueron internos: (i) la captura de posiciones y recursos claves por los miembros de la coalición dominante y (ii) el surgimiento de conflictos y polarizaciones entre las coaliciones del subsistema. Los resultados mostraron: (i) el ascenso de un subsistema de política ambiental hipercontradictorio; (ii) el realineamiento de las coaliciones no dominantes en una dirección cooperativa; (iii) la imposición de claras barreras en los procesos de negociación; y (iv) cambios en el uso de información científica por discursos más politizados con un alto grado de sesgo. Este artículo contribuye a la comprensión de los procesos de cambio institucional en la política ambiental, especialmente en contextos de cambios de gran escala generados por un aumento en la polarización electoral e intensas disputas políticas. También contribuye al análisis de los límites y posibilidades del ACF en la agenda ambiental brasileña.

Palabras clave: política ambiental; cambio de políticas; advocacy coalition framework; política brasileña. 


\section{Large-scale environmental policy change: analysis of the Brazilian reality}

The Brazilian presidential elections of 2018 brought large-scale changes in the Brazilian environmental policy subsystem. The purpose of this article is to analyze these changes through the lenses of the Advocacy Coalition Framework - ACF. First, we introduced some of the main characteristics of this subsystem, then we presented a hemerographic analysis to describe and analyze the effects of four recent shocks in this subsystem. Two of these shocks were external: (i) the election of a new political elite in power that brought a clear discourse of denial of the relevance of environmental policy and (ii) calamitous environmental events that occurred in Brazil in 2019. The other two shocks were internal: (i) the capture of key positions and resources by dominant coalition members and (ii) the rise of conflict and polarization among the coalitions in the subsystem. The results showed: (i) the rise of a hyper-adversarial environmental policy subsystem; (ii) a realignment between non-dominant coalitions in a cooperative direction; (iii) the imposition of clear barriers to negotiation; (iv) changes in the use of scientific information by more politicized discourses with a high degree of bias. The article contributes to the understanding of the processes of institutional change in environmental policy, especially in contexts of large-scale change generated by increasing electoral polarization and fierce political disputes. It also contributes to the analysis of the limits and possibilities of the ACF in the Brazilian environmental agenda.

Keywords: environmental policy; policy change; advocacy coalition framework; Brazilian politics.

\section{INTRODUÇÃO}

O Brasil é o quinto maior país do mundo, com sete biomas muito diferentes e cerca de $20 \%$ da diversidade biológica do planeta, incluindo quase 2/3 da Floresta Amazônica. O país tem a maior quantidade de água doce do mundo, o maior número de povos indígenas isolados e tem sido um importante ator na governança global do clima. Portanto, a política ambiental brasileira é uma preocupação estratégica não só para o país, mas para o mundo (Rochedo et al., 2018).

O subsistema de política ambiental no Brasil é complexo e mudou muito nos últimos trinta anos. Apesar das contínuas tensões, competições e fragilidades na sua implementação, o país conseguiu produzir e implementar uma extensa estrutura administrativa e jurídica para a proteção dos recursos naturais (Viola \& Franchini, 2017).

Desde janeiro de 2019 o governo de Jair Bolsonaro vem promovendo mudanças profundas e sem precedentes na condução do subsistema de política ambiental brasileira. Uma mudança em grande escala vem ocorrendo desde a eleição desse governo conservador, que alterou radicalmente a narrativa oficial da política ambiental, bem como a distribuição de seus recursos políticos (Hunter \& Power, 2019). O subsistema ambiental brasileiro está desestabilizado (Meeus, 2019) e sofre com incidentes recentes como desastres ambientais e aumento do desmatamento e queimadas.

O Advocacy Coalition Framework - ACF é um dos frameworks mais utilizados para explicar mudanças em políticas públicas com alto grau de competição e rivalidade (Weible \& Ingold, 2018). Com aplicações relevantes no Brasil (Carvalho, 2001; A. Soares, 2016; Souza \& Secchi, 2014), o ACF se destaca no que diz respeito às suas aplicações na política ambiental (Capelari, Araújo, \& Calmon, 2015; Weible, Heikkila, Ingold, \& Fischer, 2016).

O objetivo desse artigo é analisar as mudanças recentes e o novo equilíbrio entre coalizões no subsistema de política ambiental brasileira sob a ótica e as categorias do ACF. As questões orientadoras do artigo foram: como podemos entender as mudanças em grande escala da política 
ambiental brasileira aplicando o ACF? Quais são as possibilidades e os limites desse framework no cenário posto?

Realizamos um estudo exploratório aplicando análise de conteúdo qualitativa a dados obtidos por meio de levantamento hemerográfico (matérias jornalísticas) entre janeiro de 2019 e janeiro de 2020. Assim, a análise hemerográfica deu suporte empírico às mudanças no equilíbrio do subsistema de política ambiental brasileira. Para a descrição desse subsistema, adotamos a configuração de coalizões de defesa apresentada por Araújo (2013).

$\mathrm{O}$ artigo contribui para o entendimento das razões e formas que ocorreram as mudanças no subsistema de política ambiental brasileira recente e para examinar a viabilidade da aplicação do ACF para analisar mudanças em grande escala no equilíbrio desse subsistema de políticas públicas em um país com democracia não consolidada.

O artigo apresenta uma revisão teórica do ACF na próxima seção. Em seguida, será apresentado o subsistema de política ambiental brasileira. Na quarta seção, argumentamos a existência de quatro mudanças (choques) de grande escala iniciadas em 2019 no subsistema de política ambiental do país. $\mathrm{Na}$ quinta seção, analisamos os efeitos desses choques na dinâmica do subsistema pela perspectiva do ACF. Por fim, a consideração final apresenta alguns tópicos para reflexão e construção de agenda de pesquisa a partir do que foi apresentado no subsistema de política ambiental brasileiro.

\section{ACF: UMA VISÃO PANORÂMICA}

O Advocacy Coalition Framework - ACF foi apresentado como um framework capaz de fornecer uma alternativa às abordagens tradicionais de análise de políticas públicas (Sabatier, 1988; Sabatier \& Jenkins-Smith, 1993, 1999). Seu objetivo é deslocar a análise do processo político de uma perspectiva linear e processual para uma abordagem ancorada na mudança, suas causas e seus efeitos (Weible \& Ingold, 2018).

Os grupos de interesse no ACF são nomeados de coalizões de advocacia (Weible, Ingold, Nohrstedt, Henry, \& Jenkins-Smith, 2019). As coalizões produzem alianças informais sobre questões políticas sendo seus membros unidos pelo compartilhamento de um conjunto de convicções e ideologias que orientam a forma como observam o mundo e como as políticas públicas devem ser moldadas. Ampliando a ideia clássica de grupos de interesses (Baumgartner \& Leech, 1998), as coalizões de advocacia podem estar presentes não apenas no poder legislativo, mas, em diferentes arenas de tomada de decisão do governo. Elas podem abranger funcionários eleitos, nomeados e de carreira do governo, cientistas e consultores, representantes de organizações privadas e sem fins lucrativos e a mídia. Nesse sentido, ao propor um conjunto mais amplo de atores que influenciam o processo político, o conceito de triângulos de ferro é expandido (Sabatier \& Jenkins-Smith, 1993) para uma perspectiva de redes de políticas públicas (Bonafont, 2004).

As diferenças ideológicas e de convicções são mais bem compreendidas no ACF por um sistema de crença de três níveis. As crenças mais arraigadas, deep core beliefs, são aquelas que orientam a visão de mundo dos atores com base em diretrizes normativas com um perfil de baixa volatilidade. Mais volátil que o deep core, o policy core lida com perspectivas normativas e empíricas, voltadas para as políticas públicas que compõem o subsistema. $\mathrm{O}$ policy core não se restringe a visões de mundo, mas a como transformar essas visões em ações concretas. As crenças de nível secundário, secundary 
beliefs, são menos enraizadas e, portanto, são mais propensas a mudar. Dizem respeito à disposição de escolher instrumentos de políticas públicas capazes de solucionar problemas e atingir metas (Weible \& Ingold, 2018).

Um dos objetivos principais do ACF é investigar mudanças e a estabilidade nas políticas públicas, contribuindo para a compreensão de sua natureza e suas causas (Jenkins-Smith, Nohrstedt, Weible, \& Ingold, 2018). Do ponto de vista do ACF, as mudanças políticas são compreendidas pelas mudanças que podem promover nos sistemas de crenças. Em outras palavras, quando as crenças do deep core são afetadas e mudam é provável que a mudança na política pública tenha sido drástica. Em contraste, as mudanças que ocorrem apenas nas crenças de nível secundário, os secundary beliefs, indicam mudanças menos abruptas. Nesse sentido, as crenças políticas foram formadas a partir do critério da suscetibilidade à mudança, o que as tornam importantes elementos para identificar e caracterizar as mudanças nos subsistemas de políticas públicas (Sabatier, 1988).

O ACF oferece quatro caminhos conceituais para promover mudanças nas políticas públicas. O primeiro está relacionado a fontes externas. Derivado de eventos externos ao subsistema ou de parâmetros relativamente estáveis, o ACF assume que mudanças no subsistema de políticas públicas ocorrem devido a choques externos, entendidos como distúrbios que estão além do controle dos atores envolvidos no subsistema à exemplo de crises, de desastres ou de mudanças nas condições socioeconômicas e nos regimes políticos (Sabatier \& Weible, 2007). O segundo caminho de mudança política ocorre por meio dos eventos internos. Exemplos de eventos internos são conflitos dentro e entre coalizões, escândalos políticos e ideias fracassadas que influenciam o repensar de crenças e convicções de atores a partir de novas visões sobre o problema, suas causas e suas implicações (Nohrstedt \& Weible, 2010; Sabatier \& Weible, 2007).

Os acordos negociados representam o terceiro caminho para mudanças nas políticas públicas a partir da visão do ACF. Esses acordos geralmente são feitos por instituições colaborativas, que conduzem o processo de negociação e facilitam os acordos entre coalizões (Jenkins-Smith, Nohrstedt, Weible, \& Ingold, 2018). O quarto caminho de mudanças nas políticas públicas está direcionado para o longo prazo e é representado pela aprendizagem orientada para as políticas públicas. O ACF define a aprendizagem orientada para as políticas públicas como "alternâncias duradouras de pensamento ou intenções comportamentais que resultam da experiência e que estão preocupadas com a obtenção ou revisão dos preceitos do sistema de crenças individuais ou coletivas" (Sabatier \& Jenkins-Smith, 1993, p. 42).

Estudos empíricos recentes do ACF acrescentaram componentes secundários para compreender as mudanças em políticas públicas. Doze componentes secundários foram adicionados para entender as mudanças no processo de política pública: (i) mudança na coalizão dominante do subsistema, (ii) mudança na distribuição de recursos entre as coalizões, (iii) abertura ou fechamento de canais de negociação, (iv) mobilização da coalizão minoritária, (v) mudança de crença da coalizão dominante, (vi) mudança de crença da(s) coalizão(ões) minoritária(s), (vii) confirmação de crença da coalizão dominante, (viii) confirmação de crença da(s) coalizão(ões) minoritária(s), (ix) mudança de estratégia da coalizão dominante, (x) mudança de estratégia da(s) coalizão(ões) minoritária(s), (xi) presença de impasses e (xii) presença de um mediador (Pierce, Peterson, \& Hicks, 2020).

Com foco na mudança em políticas públicas e nos caminhos conceituais que promovem mudanças, a próxima seção descreverá a composição do subsistema de política ambiental no Brasil recente. 


\section{SUBSISTEMA DE POLÍTICA AMBIENTAL NO BRASIL: BREVE REVISÃO}

As políticas ambientais são geralmente caracterizadas por um alto grau de complexidade e conflito (Caldwell, 1993). Elas abrangem um grande número de problemas e fenômenos socioambientais que interagem em múltiplas escalas de tempo e espaço, como poluição, mudanças climáticas, desmatamento e redução da biodiversidade.

Ao buscar promover a sustentabilidade nas interações socioambientais, a política ambiental permeia, questiona e mobiliza um grande número de áreas de conhecimento, ideologias, crenças, atores, fronteiras geográficas, atividades humanas, setores econômicos e subsistemas de políticas públicas. Ainda que possa existir um consenso de que a política ambiental pode ser reconhecida como um sistema regulatório, um aparato administrativo, um conjunto de ideias, de crenças e de conhecimentos especializados, e um local de contestação e decisão, o que os governos devem fazer tem um foco contínuo de discussão e disputa científica e política (Duit, Feindt \& Meadowcroft, 2016).

Uma questão polêmica e recorrente são as restrições da regulação ambiental ao crescimento econômico, por exemplo, impedindo ou limitando o acesso aos recursos naturais e impondo a internalização de custos. As respostas a esta e outras controvérsias originaram-se de diferentes posições e crenças sobre o que deveria ser sustentabilidade, justiça ambiental e qual é o papel do Estado na proteção e distribuição dos recursos naturais (Hopwood, Mellor, \& O'Brien, 2005). Essas posições e crenças serão incorporadas por coalizões de defesa que procuram influenciar as decisões no subsistema de política ambiental.

O trabalho de Araújo (2013) é uma das aplicações mais completas do ACF na política ambiental brasileira. Seu estudo foi baseado em uma análise extensa e detalhada de audiências no Congresso relacionadas às principais decisões que afetaram o subsistema da política ambiental brasileira entre 1992 e 2012. O trabalho detectou a presença de quatro coalizões que influenciaram a chamada "agenda verde" no Brasil, a saber (Quadro 1):

\section{QUADRO 1 SUBSISTEMA DA POLÍTICA AMBIENTAL BRASILEIRA - SISTEMA DE CRENÇAS DAS QUATRO COALIZÕES DE ADVOCACIA}

\begin{tabular}{|c|c|c|c|}
\hline \multicolumn{4}{|c|}{ Subsistema da Política Ambiental Brasileira } \\
\hline Tecnocratas Esclarecidos & Socioambientalistas & Desenvolvimentistas Modernos & $\begin{array}{c}\text { Desenvolvimentistas } \\
\text { Tradicionais }\end{array}$ \\
\hline $\begin{array}{l}\text { Prioridade para a } \\
\text { preservação dos recursos } \\
\text { naturais }\end{array}$ & $\begin{array}{l}\text { Foco na conciliação entre uso } \\
\text { sustentável e preservação }\end{array}$ & $\begin{array}{l}\text { Foco no uso sustentável dos } \\
\text { recursos naturais }\end{array}$ & $\begin{array}{l}\text { Visões sobre os recursos } \\
\text { naturais que tendem ao } \\
\text { utilitarismo pro }\end{array}$ \\
\hline $\begin{array}{l}\text { Defesa de um Estado } \\
\text { caracterizado mais por sua } \\
\text { atuação vigorosa do que por } \\
\text { sues aspectos democráticos }\end{array}$ & $\begin{array}{l}\text { Enfase nos processos } \\
\text { democráticos e participativos }\end{array}$ & Defesa de um Estado mínimo & $\begin{array}{l}\text { Defesa de um Estado } \\
\text { com presença marcante } \\
\text { ao fomento às iniciativas } \\
\text { privadas }\end{array}$ \\
\hline
\end{tabular}




\begin{tabular}{|c|c|c|c|}
\hline \multicolumn{4}{|c|}{ Subsistema da Política Ambiental Brasileira } \\
\hline Tecnocratas Esclarecidos & Socioambientalistas & Desenvolvimentistas Modernos & $\begin{array}{l}\text { Desenvolvimentistas } \\
\text { Tradicionais }\end{array}$ \\
\hline $\begin{array}{l}\text { Prioridade para o } \\
\text { conhecimento técnico- } \\
\text { científico }\end{array}$ & $\begin{array}{l}\text { Valorização do saber e dos } \\
\text { direitos tradicionais }\end{array}$ & $\begin{array}{l}\text { Prioridade para o } \\
\text { conhecimento técnico- } \\
\text { científico }\end{array}$ & $\begin{array}{l}\text { Valorização dos } \\
\text { aspectos culturais (ou, } \\
\text { desconsideração do } \\
\text { conhecimento como valor) }\end{array}$ \\
\hline $\begin{array}{l}\text { Tendência ao entendimento } \\
\text { de que as decisões } \\
\text { governamentais devem } \\
\text { estar centralizadas nas } \\
\text { União }\end{array}$ & $\begin{array}{l}\text { Defesa da atuação integrada } \\
\text { dos diferentes níveis de } \\
\text { governo }\end{array}$ & $\begin{array}{l}\text { Defesa da descentralização } \\
\text { ponderada das decisões } \\
\text { governamentais }\end{array}$ & $\begin{array}{l}\text { Defesa da descentralização } \\
\text { para estado e municípios } \\
\text { das decisões relacionadas à } \\
\text { política ambiental }\end{array}$ \\
\hline $\begin{array}{l}\text { Enfase nos instrumentos } \\
\text { regulatórios }\end{array}$ & $\begin{array}{l}\text { Valorização dos diferentes } \\
\text { tipos de instrumento de } \\
\text { política ambiental }\end{array}$ & $\begin{array}{l}\text { Valorização enfática dos } \\
\text { instrumentos econômicos de } \\
\text { política ambiental }\end{array}$ & $\begin{array}{l}\text { Oposição aos instrumentos } \\
\text { da política ambiental e às } \\
\text { unidades de conservação }\end{array}$ \\
\hline & $\begin{array}{l}\text { Preocupação elevada com } \\
\text { as peculiaridades regionais e } \\
\text { locais }\end{array}$ & $\begin{array}{l}\text { Defesa da ampla participação } \\
\text { do setor privado na solução } \\
\text { dos problemas ambientais }\end{array}$ & \\
\hline
\end{tabular}

Fonte: Araújo (2013).

Os Desenvolvimentistas Tradicionais, coalizão de advocacia dominante no atual subsistema de política ambiental brasileira, são sucessores de um legado do modelo agroexportador, que concentra terras (recursos naturais), utiliza de trabalho escravo e se caracteriza pelo conservadorismo político. Com a urbanização e industrialização do país, grandes produtores de café da Primeira República, por exemplo, perderam influência na condução das políticas de Estado, mas permaneceram como importante força política e econômica do país. $\mathrm{Na}$ atualidade, poderosos complexos produtores de commodities agrícolas (por exemplo, carnes, soja, madeira e açúcar) e minerais (ferro, bauxita, manganês e nióbio) ocupam posições de destaque nessa coalizão, formada por capitais nacionais e multinacionais (Pádua, 2018).

Os Desenvolvimentistas Tradicionais foram um dos principais integrantes de um movimento neoconservador e neoliberal que venceu as eleições presidenciais brasileira de 2018. Internamente, esse movimento reúne, além do agronegócio, uma representação expressiva de militares, evangélicos, poderosos empresários que compartilham crenças, como anti-esquerdismo, autoritarismo, redução da intervenção estatal e das políticas sociais e abertura de mercado. Externamente, a coalizão dominante se beneficiou e se alinhou com a onda neoconservadora liderada pelo presidente dos EUA (Hunter \& Power, 2019). Os Desenvolvimentistas Tradicionais sempre pressionaram por uma fraca regulamentação e implementação da legislação ambiental, especialmente a federal (Dean, 1997). 
A pressão internacional, a opinião pública e os movimentos socioambientais contribuíram, em um contexto de redemocratização, para a expansão da estrutura institucional, para a "inundação" da legislação ambiental (Dryzek, 1992), bem como para organizar as outras três coalizões no subsistema de política ambiental nacional (Tecnocratas Esclarecidos, Socioambientalistas e Desenvolvimentistas Modernos) (Hochstetler \& Keck, 2007).

Os avanços na política ambiental brasileira têm gerado conflitos e tensões permanentes e crescentes entre o subsistema de política ambiental e os setores produtivos e outros subsistemas responsáveis pela expansão econômica, como agricultura, infraestrutura, indústria e outros (Ames, 2019).

A contraofensiva da coalizão dos Desenvolvimentistas Tradicionais se intensificou a partir de 2008, exigindo o relaxamento de importantes legislações regulatórias: licenciamento ambiental, novo código florestal, autorização de agrotóxicos, redução de terras indígenas e outras áreas protegidas. O principal marco e vitória dessa contraofensiva foi a reforma do novo código florestal brasileiro de 1965, que deu origem à Lei de Proteção a Vegetação Nativa (Lei 12.651/2012), que, apesar de argumentos contrários de cientistas e especialistas, aumentou o uso produtivo de áreas protegidas e anistiou infratores (B. Soares et al., 2014).

Com a ascensão de Jair Bolsonaro ao cargo de presidente, a coalizão dos Desenvolvimentistas Tradicionais passou a ocupar espaços estratégicos nos setores da economia e da política ambiental do governo federal, para iniciar uma fase que já pode ser caracterizada como um dos desmantelamentos mais explícitos da história da política ambiental federal brasileira, aumentando as tensões com especialistas, opinião pública e movimentos ambientalistas.

Assumiremos, para fins de análise das mudanças das políticas ambientais sob a perspectiva do ACF, que as quatro coalizões tratadas no Quadro 1 são representativas do subsistema da política ambiental brasileira atual mesmo após as recentes mudanças em grande escala, apresentadas em maiores detalhes na próxima seção.

\section{POLÍTICA AMBIENTAL BRASILEIRA: MUDANÇAS RECENTES (CHOQUES) A PARTIR DA PERSPECTIVA DO ACF}

O subsistema de política ambiental no Brasil passou por mudanças abruptas e em grande escala a partir de 2019. Destacaremos essas mudanças utilizando a categoria "choques", conforme proposto pelo ACF. A discussão se concentrará nos choques externos e internos relativos ao subsistema.

Os choques internos estão relacionados a dois aspectos: (i) crescimento do recurso de poder da coalizão dominante (Desenvolvimentistas Tradicionais) e (ii) falta de influência reputacional pela coalizão dominante.

(i) Os recursos de poder dos Desenvolvimentistas Tradicionais foram aumentados após a eleição de 2018. Vários fatores explicam essa expansão: o primeiro foi o aumento do número de cadeiras controladas pela Bancada Ruralista no Congresso Nacional. A fatia das cadeiras controladas pelos "ruralistas" alcançou 44\% das cadeiras da Câmara e 39,5\% das cadeiras do Senado Federal (Congresso Em Foco, 2019a). Esse aumento da influência política foi suficiente, por exemplo, para ser restaurada a Comissão Especial do Congresso sobre Mudanças Climáticas e, em seguida, nomearem como presidente desta comissão alguém que não acredita na urgência de medidas voltadas para mitigar os efeitos das mudanças climáticas (Shalders, 2019).

Além da distribuição de cadeiras no Congresso, também ocorreram mudanças importantes no Poder Executivo que fortalecem o discurso e os valores da coalizão Desenvolvimentista Tradicional. 
O novo presidente e seus nomeados políticos foram críticos ferrenhos das políticas e instituições ambientais mesmo antes de assumirem seus postos. Eles denunciavam os grupos políticos associados ao movimento ambientalista como oportunistas e corruptos sem qualquer prova explícita. O presidente foi e é contra a maioria das regulamentações ambientais existentes e frequentemente denuncia os órgãos ambientais existentes relatando que fazem parte de um grupo de "indústria de multas ambientais" (Dunder, 2019) que inibe o investimento e o crescimento econômico do país. Além disso, ele e seus ministros criticaram a quantidade e o tamanho das terras indígenas e unidades de conservação ambiental existentes no Brasil (Carta Capital, 2018), e anunciaram a intenção de reformar a legislação vigente sobre $\mathrm{o}$ assunto.

Os membros da coalizão Desenvolvimentistas Tradicionais ganharam, complementarmente, acesso e controle de informações técnicas e as têm usado para influenciar a opinião pública. Devemos citar o caso dos dados fornecidos pelo Sistema de Monitoramento da Floresta Amazônica, que utiliza informações de satélite de sensoriamento remoto para monitorar o desmatamento no bioma, cobrindo uma área de 4,7 milhões de quilômetros quadrados. O Sistema é gerenciado pelo Instituto Nacional de Pesquisas Espaciais (INPE). O INPE foi criado em 1971 e atualmente é uma unidade de pesquisa do Ministério da Ciência e Tecnologia. Em agosto de 2019, o chefe do órgão foi demitido pelo Ministério da Ciência e Tecnologia após divergência pública com o presidente sobre a validade dos dados do Sistema de Monitoramento do Desmatamento da Amazônia. O presidente argumentou que os dados que mostram o aumento do desmatamento e das queimadas na região foram alterados para atacar seu governo (Congresso Em Foco, 2019b).

(ii) Um segundo choque interno percebido no subsistema de política ambiental, também relacionado ao aumento do controle de recursos de poder pela coalizão dominante, é um movimento paradoxal. Por um lado, a coalizão Desenvolvimentistas Tradicionais ganhou o controle de alguns dos recursos de poder e posições estratégicas mais valiosos no subsistema de política ambiental. Por outro lado, a reputação desta coalizão perdeu força. As ações desse grupo passaram a ser mais fortemente questionadas do ponto de vista técnico, inclusive com efeitos negativos sobre as vendas de produtos brasileiros no mercado internacional (Vieira, 2019).

Desde o início de 2019, houve um enorme realinhamento e uma disputa altamente contenciosa entre os membros da coalizão dominante e os membros de todas as outras três coalizões existentes no subsistema da política ambiental brasileira (Tecnocratas Esclarecidos, Socioambientalistas e Desenvolvimentistas Modernos). Um exemplo concreto disso foi a construção inédita de uma frente composta por oito ex-ministros do Meio Ambiente para assinar uma carta aberta de protesto alertando sobre a "política sistemática, constante e deliberada de desconstrução e destruição das políticas ambientais" (Gortázar, 2019). Outro exemplo foi a carta de protesto dirigida ao Ministro do Meio Ambiente e confeccionada pela Associação Nacional de Servidores de Carreira de Meio Ambiente (Ascema Nacional), que o chamaram de "ardiloso, falacioso e grosseiro" depois que o Ministro publicamente ameaçou investigar a conduta de agentes públicos ambientais (Calcagno, 2019). Na mesma linha, um grupo de organizações não governamentais organizou ofensivas contra a estrutura de gestão do governo que eles chamam de "anti-política ambiental" (Girardi, 2019).

Com relação aos choques externos, pelo menos dois merecem destaque: (i) mudanças importantes na orientação ideológica do Poder Executivo federal, caracterizadas pelo autoritarismo e forte compromisso com a liberalização econômica e desconsideração dos impactos ambientais; (ii) e os desastres ambientais ocorridos no Brasil no ano de 2019. 
(i) A ascensão de uma nova elite política ao poder, no papel de coalizão dominante no subsistema de política ambiental, trouxe mudanças também nas políticas econômicas e regulatórias, com forte ênfase na liberalização e privatização e no desmantelamento do chamado "Estado Administrativo". Essa mudança também afetou muitos aspectos do subsistema ambiental. O perfil de privatizações foi observado na gestão dos parques nacionais (NexoJornal, 2019), na redução das multas ambientais para viabilizar a participação de empresas privadas (Prizibisczki, 2019) e na defesa da liberalização das atividades mineradoras e agrícolas na região Amazônica e em Terras Indígenas (Vilela, 2019). Além disso, essas mudanças também foram observadas na intenção de contratação de empresas privadas para monitorar o desmatamento da Amazônia $(\mathrm{G} 1,2019)$ e nas mudanças do atual marco regulatório do saneamento, a fim de criar incentivos para a privatização da água permitindo que empresas privadas controlem o abastecimento de água e serviços de saneamento em municípios brasileiros (Pupo, 2019).

Ao mesmo tempo, houve movimentos da coalizão dominante em direção à desmobilização e inibição da participação popular nas decisões de políticas públicas de meio ambiente. O discurso presidencial mostrou claramente o desconforto do governo com a participação das ONGs no processo político (Pereira, 2019). O chefe do Executivo Federal culpou as ONGs primeiro pelo aumento do número de incêndios na floresta amazônica (Mazui, 2019b) e, em seguida, pelos derramamentos de óleo na costa brasileira (Moreira, 2019). A interrupção do financiamento do Fundo Amazônia em 2019 (Figueiredo, 2019b) foi em grande parte devido à suspeita do Ministério do Meio Ambiente sobre a existência de inconsistências nos contratos com ONGs (Figueiredo, 2019a) - o que foi desmentido momentos depois pelos financiadores internacionais (Trigueiro, 2019).

Além da relação conturbada com o terceiro setor, a nova elite política se movimentou para reduzir a participação da sociedade civil nos processos políticos. Esse movimento conquistou a desidratação numérica do Conselho Nacional do Meio Ambiente (B. Soares, 2019), o que na prática inviabilizou o funcionamento desse colegiado por meio de câmaras técnicas, bem como a extinção de diversos comitês colegiados que auxiliam na gestão ambiental do Brasil (Grandelle, 2019).

(ii) Choques externos ligados a desastres têm pressionado o subsistema de política ambiental, com potencial para promover mudanças. Somente em 2019, ocorreram três grandes desastres ambientais no Brasil: o rompimento de uma barragem no estado de Minas Gerais (MG), o desmatamento e queimadas na floresta Amazônica e o surgimento de derramamento de óleo no litoral nordestino.

O rompimento da barragem B1, na Mina Córrego do Feijão, em Brumadinho (MG), foi considerado um grande desastre ambiental, com mais de 270 mortos (Cordeiro, 2019). A Mina Córrego do Feijão é administrada pela mineradora multinacional Vale S.A. Outrora estatal, a Vale S.A. hoje opera em trinta países e é listada nas Bolsas de Valores de São Paulo, Nova York, Hong Kong, Jacarta, Paris e Madrid. Pelas investigações realizadas até agora, tratava-se de uma tragédia anunciada, pois a Vale S.A. sabia que a barragem estava instável meses antes do rompimento (Câmara dos Deputados, 2019). Embora o governo federal tenha respondido imediatamente para ajudar as vítimas do desastre, ele se afastou dos programas de monitoramento de reparos socioambientais e indenizações, delegando ao estado de Minas Gerais toda a responsabilidade nesse sentido (Câmara dos Deputados, 2019).

O desmatamento e as queimadas na Amazônia formam o segundo choque externo que tencionou o subsistema de política ambiental brasileiro em 2019. O aumento de $30 \%$ no desmatamento na Amazônia (Oliveira \& Matos, 2020), esteve associado ao número recorde de focos de incêndio na região (O Globo, 2019). Além do desmatamento e das queimadas na Amazônia, a forma como o governo federal tratou o problema gerou inúmeras críticas da comunidade científica e ambientalista 
e fortes críticas das três coalizões não dominantes do subsistema. O ministro do Meio Ambiente, por exemplo, disse que a associação entre incêndios florestais e o clima na cidade de São Paulo era fake news (Toledo, 2019), apontou problemas nas ações promovidas pelos governos estaduais para conter os focos de incêndio (Turollo \& Fernandes, 2019) e disse que os focos de incêndios aumentaram porque a região passava por um período de seca (TV Cultura, 2019), tese que não foi comprovada por dados científicos (Marés, Moraes, \& Afonso, 2019). O presidente afirmou que a floresta não estava pegando fogo, mas sim as áreas de pastagem (Mazui, 2019a), outra tese desmentida por pesquisadores nacionais e internacionais (Mendes, 2019).

Um terceiro choque externo esteve associado ao vazamento de óleo nas praias do Nordeste do Brasil. Tal vazamento tem sido considerado o maior desastre ambiental já sofrido pelo país, semelhante ao derramamento no Golfo do México em 2010 (Valor, 2019). Como no caso dos incêndios, a atenção não estava apenas no desastre, mas na fraca ação governamental para sua contenção. Houve fortes críticas ao governo federal pela demora na promoção de ações para mitigar o desastre. O Ministério Público Federal ajuizou ação contra a União (DW, 2019), foi criada uma Comissão de Inquérito no Senado Federal (Madeiro, 2019) e outra na Câmara dos Deputados (Vivas, 2019) para investigar a omissão do Estado em agir sobre a tragédia. Cercado de críticas, o Ministro do Meio Ambiente responsabilizou os vizinhos venezuelanos (Agência Brasil, 2019) e o Greenpeace (Barbosa, 2019) pelo desastre.

Na próxima seção, discutiremos o impacto dos quatro choques no subsistema de política ambiental brasileira de acordo com a perspectiva do ACF.

\section{MUDANÇA EM POLÍTICAS PÚBLICAS: DISCUSSÃO TEÓRICA SOBRE OS RECENTES CHOQUES NA POLÍTICA AMBIENTAL BRASILEIRA}

Não é fácil analisar as mudanças em grande escala na política ambiental brasileira pela natureza inconclusiva dos eventos e seus efeitos incompletos sobre a estrutura do subsistema ambiental. A eleição de 2018 trouxe ao poder uma coalizão Desenvolvimentista Tradicional, alterando o equilíbrio do subsistema ambiental e criando uma nova dinâmica para mudanças políticas. Em suma, analisaremos quatro implicações principais para o debate teórico do ACF: (i) o surgimento de um subsistema de política ambiental hiperadversarial; (ii) um realinhamento entre coalizões não dominantes na direção cooperativa; (iii) a imposição de barreiras claras à negociação; e (iv) mudanças no uso da informação científica por discursos mais politizados e com alto grau de vieses.

(i) O surgimento de um subsistema de política ambiental hiperadversarial. A capacidade dos atores políticos de produzir e moldar os resultados das políticas públicas é influenciada pela forma como o ator é percebido por seus pares no processo de tomada de decisão. O poder dos tomadores de decisão é fundamental para os resultados e a legitimidade da política e está relacionado a pelo menos dois critérios: sua reputação ou influência estrutural e sua autoridade formal ou influência institucional (Ingold \& Leifeld, 2014).

Na seção anterior mostramos o baixo nível de reputação da coalizão dominante entre os atores pertencentes ao subsistema de política ambiental no Brasil. O encontro de oito ex-Ministros de Meio Ambiente em um discurso contrário ao que é praticado pelo atual Ministro do Meio Ambiente, as críticas produzidas pela Associação Nacional de Carreiras Ambientais e por ONGs ao mesmo Ministro de Meio Ambiente, são exemplos concretos da falta de influência da reputação da coalizão dominante. 
As críticas são tão difundidas que muitas vezes geram repercussões nas redes sociais apresentando Ricardo Salles como um anti-Ministro de Meio Ambiente (O Globo, 2019d).

A deficiência de reputação da coalizão dominante no subsistema impacta negativamente a eficácia e a legitimidade da tomada de decisão no setor público (Watkins \& Rosegrant, 1996). Soma-se a isso o estilo autoritário e muitas vezes revanchista da coalizão dominante que tem fomentado a polarização e o surgimento do conflito em um subsistema político já caracterizado por intensas disputas (Muta, 2019).

Nesse sentido, os conflitos passam a ser a regra e não a exceção na política ambiental brasileira, que parece ter transitado de um contorno adversarial para um subsistema de política hiperadversarial. Um subsistema político altamente conflitivo e hiperadversarial cria uma forte divergência na posição política e na coordenação entre coalizões, reduzindo os canais de negociação (Weible, Heikkila, \& Pierce, 2018) ao expandir as ameaças e a falta de vontade entre as coalizões (Heikkila \& Weible, 2017).

O subsistema de política ambiental brasileira pode ser um grande exemplo para testar hipóteses e melhorar algumas agendas de pesquisa sobre conflito em políticas públicas. Os estudos do ACF dão atenção limitada aos subsistemas conflituosos e hiperadversários, bem como suas implicações para as mudanças em políticas públicas (Weible \& Heikkila, 2017).

(ii) Realinhamento entre coalizões não dominantes em direção a uma maior cooperação. Embora a coalizão dominante tenha fragilidades de reputação no subsistema de política ambiental brasileira, ela tem autoridade formal ou influência institucional (Ingold \& Leifeld, 2014). A autoridade formal permite que uma coalizão dominante tenha acesso a recursos políticos, aumente a influência política no Congresso Nacional e altere estruturas e agentes públicos de acordo com seu interesse particular (Primavera, 2020b). Assim, a coalizão dominante vem frequentemente impondo suas crenças e ideias sobre a política ambiental brasileira, mesmo sem o apoio ou concordância das outras três coalizões de defesa que atuam no subsistema.

Em resposta a esse cenário, as outras três coalizões de defesa, que não são dominantes (Tecnocratas Esclarecidos, Socioambientalistas e Desenvolvimentistas Modernos) iniciaram um aparente realinhamento em torno da cooperação entre si e em oposição à coalizão dominante e, mais do que isso, contra a narrativa do presidente e seus aliados sobre o direcionamento da política ambiental brasileira. Esse realinhamento sem precedentes entre ambientalistas que possuem diferentes pontos de vista torna explícito um esforço claro de coalizões não dominantes no sentido de (re) construir novos canais de articulação e negociação (Adshead, 2011; Sabatier \& Jenkins-Smith, 1993). Com a união das três coalizões, sem ainda descaracterizar suas diferenças e convicções políticas, eles se fortalecem no conflito dentro do subsistema que vem ocorrendo desde janeiro de 2019.

Além disso, o recente realinhamento entre coalizões não dominantes representa um movimento em direção ao aprendizado voltado para políticas públicas no subsistema de política ambiental brasileiro (Moyson, 2017). Esse processo de aprendizagem envolve a redução das diferenças entre essas três coalizões em favor da redução do conflito no subsistema de política ambiental. Os sinais de cooperação indicam que um esforço para reduzir as perdas às instituições ambientais no Brasil depende de um acordo negociado em torno de uma agenda ambiental positiva, capaz de competir com o poder da narrativa e da agenda formal da coalizão dominante.

Se esse movimento de cooperação entre as três coalizões não dominantes está relacionado à categoria "devil shift" do ACF (Sabatier, Hunter, \& McLaughlin, 1987), a desastres ambientais recorrentes ou a um aumento na convergência de crenças políticas entre essas três coalizões rivais 
(Jenkins-Smith, Nohrstedt, Weible, \& Sabatier, 2014; Kettell \& Cairney, 2010; Weible \& Sabatier, 2009), são questões relevantes a serem investigadas em pesquisas futuras.

(iii) Imposição de barreiras à negociação. A redução do Conselho Nacional do Meio Ambiente representa um exemplo claro dessa barreira, bem como o discurso público da coalizão dominante contra as ONGs, os dados científicos e a favor da redução da transparência no serviço público ambiental, todos mostrado na seção anterior. Esse movimento que reforça um perfil de impasse no subsistema de política ambiental brasileira (Sabatier \& Weible, 2007) foi discutido em alguns outros estudos empíricos (Frahsa, Rütten, Abu-Omar, \& Schow, 2014; Heikkila et al., 2014).

Depois de assumir a autoridade formal no subsistema ambiental brasileiro, a coalizão Desenvolvimentistas Tradicionais parece não ter intenção de criar canais de negociação e acordos com as outras três coalizões não dominantes. Em vez disso, a coalizão dominante tem preferido impor decisões unilaterais ou negociar com coalizões pertencentes a outros subsistemas (agricultura, mineração e militar). Esse tipo de comportamento induz uma reflexão sobre o estudo da categoria “dialogue of deaf" presente no ACF (Sabatier, 1988) que ainda é pouco aplicada e discutida.

Uma barreira à negociação imposta pela coalizão dominante no subsistema ambiental brasileiro foi a redução na influência da sociedade civil e de atores especializados na produção e mudança de políticas públicas. Como mencionado anteriormente, uma das ideias mais importantes do ACF é a expansão do número de atores envolvidos no subsistema de políticas públicas para além do "triângulo de ferro" (Weible \& Sabatier, 2009). O fechamento político à participação da sociedade civil que está ocorrendo atualmente no subsistema ambiental brasileiro vai de encontro à consolidação de uma ampla e especializada rede de atores. Essa ambiguidade poderia gerar uma discussão sobre a adesão do ACF em um pluralismo não consolidado (John, 2003) fora da Europa Ocidental e da América do Norte (Henry, Ingold, Nohrstedt, \& Weible, 2014), bem como sobre a capacidade de grupos marginalizados influenciar o processo de formulação de políticas (Holmes \& Scoones, 2001), especialmente em países caracterizados pela profunda desigualdade social como o Brasil (Souza, 2004).

Além disso, ao priorizar a análise institucional de nível médio e micro, o ACF não se concentra no plano macroestrutural ou histórico (Ianoni, 2017) o que, no caso do Brasil, implica desconsiderar ou marginalizar o legado de uma cultura extrativista e de uma estrutura econômica balizada na agroexportação e suas relações historicamente complicadas com a proteção ambiental.

(iv) Mudanças no uso da informação científica a partir de discursos mais politizados e com alto grau de vieses. Essas mudanças foram discutidas na seção anterior quando a coalizão dominante colocou em dúvida os números do desmatamento na Amazônia, demitiu o presidente do INPE, acusou inconsistências no contrato com o Fundo Amazônia e ONGs, culpou as ONGs primeiro pelo aumento no número de incêndios na floresta amazônica e, depois, pelos derramamentos de óleo na costa brasileira. Essa forma de atuação consolida a despreocupação com o uso de embasamento científico nas narrativas, o que não ocorria, pelo menos não neste grau, antes de 2019.

Esse movimento, produzido pela coalizão dominante, representa uma estratégia de desconstrução da informação facilitando a introdução de novas crenças e ideias no processo político. O uso de informações pela coalizão Desenvolvimentistas Tradicionais frequentemente está relacionado com notícias falsas, anticientífica, vinculada a mídias não tradicionais e com alto grau de componentes de negação de crises ambientais (Benites, 2018). Esse tipo de estratégia da coalizão dominante parece estar relacionado ao componente secundário de mudanças políticas proposto pelo ACF (Pierce, Peterson, \& Hicks, 2020). 
A informação enviesada usada como estratégia de coalizão dominante tem duas implicações. Primeira, pode estar associada com a mobilização da opinião pública. Conforme discutido anteriormente, a ausência de influência reputacional da coalizão dominante dentro do subsistema da política ambiental brasileira, mesmo com a força do poder formal, implica na redução da legitimidade da coalizão dominante e também dificulta seu desempenho prático (o que pode até levar a resposta ineficaz a desastres, conforme mencionado). Ao enviesar as informações científicas e oficiais, a coalizão Desenvolvimentistas Tradicionais aposta em legitimar suas ações por meio da conquista da opinião pública desinformada. Na perspectiva do $\mathrm{ACF}$ a opinião pública é um importante recurso da coalizão para aumentar seu poder, sua capacidade de influência e sua probabilidade de ganhar a competição no subsistema e assim impor seus desejos, interesses e crenças no processo de tomada de decisão (Weible \& Ingold, 2018).

A segunda implicação diz respeito ao impacto das distorções da informação científica no sistema de crenças do subsistema de políticas públicas ambientais no Brasil. Embora o ACF tenha previsto, em certa medida, vieses e uso político da informação como estratégias concorrenciais das coalizões nos subsistemas políticos, seus estudos analisaram o impacto dos vieses nas crenças do policy core e dos secundary beliefs. Para esses dois níveis de crença a discussão das estratégias de vieses e do uso político delas está na forma de como será a intervenção no problema público (Montpetit, 2011). No entanto, no subsistema da política ambiental brasileira atual, os vieses e o uso político da informação passam a ser aplicados nas crenças do deep core. Este cenário permite que a coalizão dominante negue os problemas públicos ambientais, como a crise ambiental e as mudanças climáticas. A estratégia negacionista dos problemas ambientais garante a inação do Estado (McConnell \& Hart, 2019), inaugura uma forma mais conflituosa de uso enviesado da informação e aumenta o avanço das forças desregulamentadoras de meio ambiente.

Na próxima seção, desenvolveremos as considerações finais.

\section{CONSIDERAÇÕES FINAIS}

Desde a redemocratização do Brasil, não vimos uma mudança em grande escala no subsistema da política ambiental como a que estamos vendo atualmente. O retorno ao poder formal de ideologias conservadoras e liberais, representadas pela coalizão Desenvolvimentistas Tradicionais, tem promovido mudanças na política ambiental por um esforço combinado de desmantelamento da política e luta contra o aprendizado, as negociações, a sociedade civil, a informação científica e os especialistas.

Neste artigo, usando as contribuições do ACF, analisamos, a partir da confluência de choques externos e internos ao subsistema, quatro implicações das mudanças de grande escala na política ambiental brasileira recente: o surgimento de um subsistema de política ambiental hiperadversário, o realinhamento entre coalizões não dominantes em uma direção cooperativa; a imposição de barreiras à negociação; e mudanças no uso da informação científica por informações mais politizadas e com alto grau de vieses.

Essas mudanças em grande escala e suas implicações desafiam a forma analítica convencional do ACF. Embora permita captar e sistematizar características importantes das mudanças ocorridas, é necessário atentar para as suas fragilidades na análise de processos políticos conduzidos em sociedades marcadas por profundas e variadas desigualdades, incluindo o acesso aos recursos naturais. Historicamente caracterizada por inequidades sociais, a realidade brasileira vem se tornando cada vez 
mais marcada pelo autoritarismo político, o que pode acentuar as dificuldades de aplicação do ACF no país. Em termos de política ambiental, se a realidade política não for revertida, o Brasil caminha para uma perspectiva de inação em políticas públicas e, talvez, de desmantelamento sem precedentes do subsistema de política ambiental.

Além dos vários tópicos já sugeridos acima, recomendamos algumas novas investigações:

(i) No subsistema hiperadversário e na ruptura com as crenças do deep core, características típicas dos padrões de tomada de decisão de ideologias conservadoras e liberais. Em termos do ACF, vale a pena perguntar quais os padrões de aprendizagem do subsistema de políticas públicas quando se tem uma coalizão dominante guiada pela violência simbólica e material? Que aprendizado é possível com uma coalizão dominante negando a legitimidade da existência do subsistema?

(ii) $\mathrm{Na}$ revitalização de crenças e articulações de coalizões não dominantes em subsistema hiperadversário. Estudar o grau de aproximação das diferentes crenças de coalizões não dominantes parece ser uma forma de entender melhor os canais de negociação em subsistemas conflituosos.

(iii) No movimento de exclusão da sociedade civil e de especialistas do subsistema de políticas públicas. É necessário detalhar a extensão dessa exclusão e seus impactos no processo político. A relação desse movimento com as categorias do ACF - conhecimento, aprendizado em políticas públicas e acordos negociados - pode construir importantes caminhos de reflexão.

(iv) Nas distorções em dados científicos, utilizando táticas como fake news, pós-verdade e negação. Todas estas táticas ainda não foram exploradas suficientemente pelo ACF. A informação cientifica é um elemento importante para compreender as mudanças políticas pela lente desse framework. Assim, a reflexão sobre os impactos de sua negação, distorção e até mesmo desvalorização nas mudanças em políticas públicas poderia ser incorporada a futuros estudos.

Os desafios para a utilização do ACF no Brasil e nos países em desenvolvimento, portanto, devem continuar a serem investigados, uma vez que possuem sistemas e subsistemas de políticas públicas, sociais e ambientais, que colocam em situação de fragilidade os pressupostos previstos no arcabouço do ACF. 


\section{REFERÊNCIAS}

Adshead, M. (2011). An advocacy coalition framework approach to the rise and fall of social partnership. Irish Political Studies, 26(1), 73-93.

Agência Brasil. (2019, 23 de outubro). Governo pede na OEA que Venezuela se manifeste sobre óleo, diz Salles. Brasília, DF: Autor. Recuperado de http:// agenciabrasil.ebc.com.br/geral/noticia/2019-10/ governo-pede-na-oea-que-venezuela-se-manifestesobre-oleo-diz-salles

Ames, B. (2019). Routledge Handbook of Brazilian Politics. London, UK: Taylor \& Francis Group.

Araújo, S. M. V. G. (2013). Política ambiental no Brasil no período 1992-2012: um estudo comparado das agendas verde e marrom. Brasília, DF: Universidade de Brasília.

Barbosa, M. (2019, 24 de outubro). Salles sugere que navio do Greenpeace derramou óleo no Nordeste. Congresso Em Foco. Recuperado de https:// congressoemfoco.uol.com.br/especial/noticias/ salles-sugere-que-navio-do-greenpeace-derramouoleo-no-nordeste/

Baumgartner, F. R., \& Leech, B. L. (1998). Basic interests: The importance of groups in politics and in political science. Princeton, NJ: Princeton University Press.

Benites, A. (2018, 28 de setembro). A máquina de 'fake news' nos grupos a favor de Bolsonaro no WhatsApp. El País. Recuperado de https://brasil.elpais.com/ brasil/2018/09/26/politica/1537997311_859341. html

Bonafont, L. C. (2004). Redes de políticas públicas. Madrid, España: Centro de Investigaciones Sociológicas.

Calcagno, L. (2019, 24 de abril). ICMBio, ligado ao Meio Ambiente, perde terceiro chefe em menos de 10 dias. Correio Braziliense. Recuperado de https://www.correiobraziliense.com.br/app/noticia/ politica/2019/04/24/interna_politica,751254/sobtensao-icmbio-perde-terceiro-chefe-em-menos-dedez-dias.shtml

Caldwell, L. K. (1993). Environmental policy as a political problem. Review of Policy Research, 12(3-4), 104-117.

Capelari, M. G. M., Araújo, S. M. V. G., \& Calmon, P. C. (2015). Advocacy Coalition Framework: um balanço das pesquisas nacionais. Administração Pública e Gestão Social, 7(2), 91-99.

Carta Capital. (2018, 26 de outubro). As ameaças de Bolsonaro ao papel central do Brasil no meio ambiente. São Paulo, SP: Autor. Recuperado de https://www. cartacapital.com.br/politica/bolsonaro-ameaca-alideranca-do-brasil-em-questoes-ambientais/

Carvalho, G. O. (2001). Metallurgical Development in the Caraja' s Area: A Case Study of the Evolution of Environmental Policy Formation in Brazil. Society \& Natural Resources, 14(2), 127-143.

Congresso Em Foco. (2019a, 02 de abril). Com 257 parlamentares, bancada ruralista declara apoio à reforma da Previdência. Brasília, DF: Autor. Recuperado de https://congressoemfoco.uol.com. br/economia/com-257-parlamentares-bancadaruralista-declara-apoio-a-reforma-da-previdencia/

Congresso Em Foco. (2019b, 02 de agosto). Diretor do Inpe é demitido após desafiar Bolsonaro. Brasília, DF: Autor. Recuperado de https://congressoemfoco. uol.com.br/meio-ambiente/diretor-do-inpe-edemitido-apos-desafiar-bolsonaro/

Cordeiro, F. (2019, 20 de novembro). No 300 dia de buscas, bombeiros encontram mais um corpo em Brumadinho. Estadão. Recuperado de https:// brasil.estadao.com.br/noticias/geral,no-300-dia-debuscas-bombeiros-encontram-mais-um-corpo-embrumadinho,70003096451

Dean, W. (1997). A Ferro e fogo: a história da devastação da mata atlântica brasileira. Rio de Janeiro, RJ: Companhia das Letras.

Deputados, C. (2019). Comissão Parlamentar de Inquérito: rompimento da barragem e Brumadinho (relatório final da CPI). Brasília, DF: Câmara dos Deputados

Deutsche Welle. (2019, 19 de outubro). MPF entra com ação contra União por omissão sobre manchas de óleo. Bonn, Germany: Autor. Recuperado de https://www.dw.com/pt-br/mpf-entra-com-açãocontra-união-por-omissão-sobre-manchas-deóleo/a-50894882

Dryzek, J. S. (1992). Ecology and discursive democracy: Beyond liberal capitalism and the administrative state. Capitalism Nature Socialism, 3(2), 18-42. 
Duit, A., Feindt, P. H., \& Meadowcroft, J. (2016). Greening Leviathan: the rise of the environmental state? Environmental politics, 25(1), 1-23.

Dunder, K. (2018, 01 de dezembro). Bolsonaro afirma que "farra das multas" ambientais vai acabar. R7. Recuperado de https://noticias.r7.com/brasil/ bolsonaro-afirma-que-farra-das-multas-ambientaisvai-acabar-01122018

Figueiredo, P. (2019a, 17 de maio). Ministro do Meio Ambiente diz ter analisado 1/4 dos contratos do Fundo Amazônia e verificado inconsistências. G1. Recuperado de https://g1.globo.com/natureza/ noticia/2019/05/17/ministro-do-meio-ambientediz-ter-analisado-14-dos-contratos-do-fundoamazonia-e-verificado-inconsistencias.ghtml

Figueiredo, P. (2019b, 12 de agosto). Fundo Amazônia não aprovou nenhum projeto em 2019. G1. Recuperado de https://g1.globo.com/natureza/ noticia/2019/08/12/estagnado-fundo-amazonianao-aprovou-nenhum-projeto-em-2019.ghtml

Frahsa, A., Rütten, A., Roeger, U., Abu-Omar, K., \& Schow, D. (2014). Enabling the powerful? Participatory action research with local policymakers and professionals for physical activity promotion with women in difficult life situations. Health promotion international, 29(1), 171-184.

Franco, B. M. (2019, 21 de abril). Um antiministro no Meio Ambiente. O Globo. Recuperado de https:// blogs.oglobo.globo.com/bernardo-mello-franco/ post/um-antiministro-no-meio-ambiente.html

Girardi, G. (2019, 21 de agosto). ONGs: "Queimadas refletem irresponsabilidade de Bolsonaro". Terra. Recuperado de https://www.terra.com.br/noticias/ ciencia/sustentabilidade/meio-ambiente/ongsqueimadas-refletem-irresponsabilidade-de-bolsonar o,f05badec3c96fb46ef5dc5b2b92d5felpty35uhy.html

G1. (2019, 21 de agosto). Ibama lança edital para contratar empresa privada para monitorar desmatamento na Amazônia. Recuperado de https:// g1.globo.com/natureza/noticia/2019/08/21/ibamalanca-edital-para-contratar-empresa-privada-paramonitorar-desmatamento-na-amazonia.ghtml

Gortázar, N. G. (2019, 08 de maio). Uma inédita frente de ex-ministros do Meio Ambiente contra o desmonte de Bolsonaro. El País. Recuperado de https://brasil.elpais.com/brasil/2019/05/08/ politica/1557338026_221578.html
Grandelle, R. (2019, 26 de outubro). Governo ignorou nota técnica que pedia recriação de comitês responsáveis por combate ao óleo. $O$ Globo. Recuperado de https://oglobo.globo.com/ sociedade/governo-ignorou-nota-tecnica-quepedia-recriacao-de-comites-responsaveis-porcombate-ao-oleo-1-24043953

Heikkila, T., Pierce, J. J., Gallaher, S., Kagan, J., Crow, D. A., \& Weible, C. M. (2014). Understanding a Period of Policy Change: The Case of Hydraulic Fracturing Disclosure Policy in C olorado. Review of Policy Research, 31(2), 65-87.

Heikkila, T., \& Weible, C. M. (2017). Unpacking the intensity of policy conflict: a study of Colorado's oil and gas subsystem. Policy Sciences, 50(2), 179-193.

Henry, A. D., Ingold, K., Nohrstedt, D., \& Weible, C. M. (2014). Policy change in comparative contexts: Applying the advocacy coalition framework outside of Western Europe and North America. Journal of Comparative Policy Analysis: Research and Practice, 16(4), 299-312.

Hochstetler, K., \& Keck, M. E. (2007). Greening Brazil: Environmental activism in state and society. Durham, NC: Duke University Press.

Holmes, T., \& Scoones, I. (2001). Participatory environmental policy processes: experiences from North and South. In M. Pimbert \& T. Wakeford. (Eds.), PLA 40: Deliberative Democracy and Citizen Empowerment. International Institute of Environment and Empowerment. London, UK: International Institute for Environment and Development, Sustainable Agriculture Programme.

Hopwood, B., Mellor, M., \& O'Brien, G. (2005). Sustainable development: mapping different approaches. Sustainable development, 13(1), 38-52.

Hunter, W., \& Power, T. J. (2019). Bolsonaro and Brazil's Illiberal Backlash. Journal of Democracy, 30(1), 68-82.

Ianoni, M. (2017). Para uma abordagem ampliada das coalizões. Sinais Sociais, 11(33), 99-129.

Ingold, K., \& Leifeld, P. (2014). Structural and institutional determinants of influence reputation: A comparison of collaborative and adversarial policy networks in decision making and implementation. Journal of Public Administration Research and Theory, 26(1), 1-18. 
Jenkins-Smith, H. C., Nohrstedt, D., Weible, C. M., \& Ingold, K. (2018). The advocacy coalition framework: An overview of the research program. In C. Weible \& P. Sabatier (Eds.), Theories of the policy process (Vol. 4, pp. 135-171). Boulder, CO: Routledge.

Jenkins-Smith, H. C., Nohrstedt, D., Weible, C. M., \& Sabatier, P. A. (2014). The advocacy coalition framework: Foundations, evolution, and ongoing research. In C. Weible \& P. Sabatier (Eds.), Theories of the policy process (Vol. 3, pp. 183-224). Boulder, CO: Routledge.

John, P. (2003). Is there life after policy streams, advocacy coalitions, and punctuations: Using evolutionary theory to explain policy change? Policy Studies Journal, 31(4), 481-498.

Kettell, S., \& Cairney, P. (2010). Taking the power of ideas seriously-the case of the United Kingdom's 2008 Human Fertilisation and Embryology Bill. Policy Studies, 31(3), 301-317.

Madeiro, C. (2019, 24 de outubro). Comissão do Senado vai apurar omissão do governo em relação a óleo no NE. UOL. Recuperado de https://noticias. uol.com.br/meio-ambiente/ultimas-noticias/ redacao/2019/10/24/comissao-do-senado-vaiapurar-omissao-do-governo-em-relacao-a-oleono-ne.htm

Marés, C., Moraes, M., \& Afonso, N. (2019, 28 de agosto). Salles erra ao dizer que seca causou aumento de queimadas na Amazônia. Lupa Piauí. Recuperado de https://piaui.folha.uol.com.br/lupa/2019/08/28/ salles-seca-queimadas-amazonia/

Mazui, G. (2019a, 24 de agosto). Bolsonaro diz que 'floresta não está pegando fogo', mas sim as áreas desmatadas. G1. Recuperado de https://g1.globo. com/politica/noticia/2019/08/24/bolsonaro-dizque-floresta-nao-esta-pegando-fogo-mas-sim-asareas-desmatadas.ghtml

Mazui, G. (2019b, 21 de agosto). Bolsonaro diz que ONGs podem estar por trás de queimadas na Amazônia para 'chamar atenção' contra o governo. G1. Recuperado de https://g1.globo.com/politica/ noticia/2019/08/21/bolsonaro-diz-que-ongspodem-estar-por-tras-de-queimadas-na-amazoniapara-chamar-atencao-contra-o-governo.ghtml
McConnell, A., \& Hart, P. t. (2019). Inaction and public policy: understanding why policymakers 'do nothing. Policy Sciences, 52(4), 645-661.

Meeus, B. (2019). Politiques environnementales au Brésil: analyse historique et récents développements sous Jair Bolsonaro. La Pensee ecologique, 2, 45-61.

Mendes, K. (2019, 28 de setembro). Estudo indica que queimadas na Amazônia ocorreram em áreas desmatadas em 2019. El País. Recuperado de https://brasil.elpais.com/brasil/2019/09/26/ politica/1569456980_698387.html

Montpetit, É. (2011). Scientific credibility, disagreement, and error costs in 17 biotechnology policy subsystems. Policy Studies Journal, 39(3), 513-533.

Moreira, M. (2019, 24 de outubro). Salles usa imagem antiga para insinuar que Greenpeace seria culpado por óleo no NE. Folha de S. Paulo. Recuperado de https://www1.folha.uol.com.br/ ambiente/2019/10/salles-usa-imagem-antiga-parainsinuar-que-greenpeace-seria-culpado-por-oleono-ne.shtml

Moyson, S. (2017). Cognition and policy change: the consistency of policy learning in the advocacy coalition framework. Policy and Society, 36(2), 320344 .

Muta,J.(2019,25deoutubro). 'Não éum ambientalista, é um impostor', diz Marina sobre Ricardo Salles. Folha de Pernambuco. Recuperado de https://folhape. com.br/politica/politica/oleo-no-litoral/2019/10/25/ BLG, 12926,7, 1577, POLITICA, 2419-NAOAMBIENTALISTA-IMPOSTOR-DIZ-MARINASOBRE-RICARDO-SALLES.aspx

Nohrstedt, D., \& Weible, C. M. (2010). The logic of policy change after crisis: Proximity and subsystem interaction. Risk, Hazards \& Crisis in Public Policy, 1(2), 1-32.

O Globo. (2019). Fogo na Amazônia: o Brasil no centro de uma crise ambiental. Jornal $O$ Globo. Recuperado de https://www.youtube.com/ watch?v=B7wlxAu2j6k

Oliveira, E., \& Matos, T. (2020, 13 de abril). Alertas de desmatamento na Amazônia batem recorde no primeiro trimestre de 2020, mostram dados do Inpe. G1. Recuperado de https://g1.globo.com/natureza/ noticia/2020/04/13/alertas-de-desmatamento- 
na-amazonia-crescem-5145percent-no-primeirotrimestre-mostram-dados-do-inpe.ghtml

Pádua, J. A. (2018). The Dilemma of the 'Splendid Cradle': Nature and Territory in the Construction of Brazil. In J. L. Soluri, C.; Pádua, J. A. (Ed.), A Living Past, Environmental Histories of Modern Latin America. New York, NY: Berghahn Books.

Pereira, C. (2019, 14 de fevereiro). As ONG’s não podem depender do governo. Istoé. Recuperado de https://istoe.com.br/as-ongs-nao-podem-dependerdo-governo/

Pierce, J. J., Peterson, H. L., \& Hicks, K. C. (2020). Policy change: an advocacy coalition framework perspective. Policy Studies Journal, 48(1), 64-86.

Prizibisczki, C. (2019, 14 de abril). Governo institui anistia prévia a criminosos ambientais. OECO. Recuperado de https://www.oeco.org.br/ reportagens/governo-institui-anistia-previa-acriminosos-ambientais/

Pupo, A. (2019, 30 de outubro). Comissão especial aprova novo marco do saneamento que prevê atuação de empresas privadas. Estadão. Recuperado de https://economia.estadao.com.br/noticias/ geral,comissao-especial-aprova-novo-marco-desaneamento-que-preve-atuacao-de-empresasprivadas,70003069955

Rochedo, P. R., Soares, B., Filho, Schaeffer, R., Viola, E., Szklo, A., Lucena, A. F. ... Rathmann, R. (2018). The threat of political bargaining to climate mitigation in Brazil. Nature Climate Change, 8(8), 695-698.

Sabatier, P. A. (1988). An advocacy coalition framework of policy change and the role of policyoriented learning therein. Policy Sciences, 21(2-3), 129-168.

Sabatier, P. A., Hunter, S., \& McLaughlin, S. (1987). The devil shift: Perceptions and misperceptions of opponents. Western Political Quarterly, 40(3), 449-476.

Sabatier, P. A., \& Jenkins-Smith, H. C. (1993). Policy change and learning: An advocacy coalition approach. Boulder, CO: Westview Press.

Sabatier, P. A., \& Jenkins-Smith, H. C. (1999). The Advocacy Coalition Framework: An Assessment. In P. A. Sabatier. (Ed.), Theories of the policy process (pp. 117-166). Boulder, CO: Westview Press.
Sabatier, P. A., \& Weible, C. M. (2007). The advocacy coalition framework: innovations and clarifications. In P. A. Sabatier (Ed.), Theories of the policy process (Vol. 2). Boulder, CO: Westview Press.

Shalders, A. (2019, 12 de setembro). Mudanças climáticas não são causadas pela ação humana, diz presidente de Comissão de Mudanças Climáticas do Congresso. BBC Brasil. Recuperado de https://www. bbc.com/portuguese/brasil-49683893

Soares, A. G. (2016). Atores e ideias na constituição do direito à Memória e à Verdade: análise da mudança política no Programa Nacional de Direitos Humanos. (Tese de Doutorado). Universidade Federal de São Carlos, São Carlos.

Soares, B., Filho, Rajão, R., Macedo, M., Carneiro, A., Costa, W., Coe, M. ... Alencar, A. (2014). Cracking Brazil's forest code. Science, 344(6182), 363-364.

Soares, I. (2019, 29 de maio). Decreto de Bolsonaro reduz composição do Conama de 96 conselheiros para 23. Correio Braziliense. Recuperado de https://www.correiobraziliense.com.br/app/noticia/ politica/2019/05/29/interna_politica,758531/ decreto-de-bolsonaro-reduz-composicao-doconama-de-100-conselheiros-pa.shtml

Souza, \& Secchi, L. (2014). Política de Ciencia y Tecnología en Santa Catarina, Brasil: análisis a partir del modelo de coaliciones de defensa. Revista de Administração Pública, 48(4), 939-960.

Souza, J. (2004). A gramática social da desigualdade brasileira. Revista brasileira de ciências sociais, 19(54), 79-96.

Spring, J. (2020a, 27 de fevereiro). Brazil Environment Ministry fires top climate change officials. Reuters. Recuperado de https://uk.reuters.com/article/ uk-brazil-environment-climatechange/brazilenvironment-ministry-fires-top-climate-changeofficials-idUKKCN20L2A6?il=0

Spring, J. (2020b, 06 de abril). Brazil minister fires analyst who opposed unAutorized wood exports. Reuters. Recuperado de https://www.reuters.com/ article/us-brazil-environment/brazil-minister-firesanalyst-who-opposed-unAutorized-wood-exportsidUSKBN21O30F

Toledo, M. (2019, 20 de agosto). Salles diz que relacionar céu escuro em SP a queimadas na Amazônia é fake news. Folha de S. Paulo. 
Recuperado de https://www1.folha.uol.com.br/ ambiente/2019/08/salles-diz-que-relacionar-ceuescuro-em-sp-a-queimadas-na-amazonia-e-fakenews.shtml

Trigueiro, A. (2019, 15 de maio). Financiadores internacionais desaprovam anúncio de ministro sobre 'irregularidades' no Fundo Amazônia. G1. Recuperado de https://g1.globo.com/natureza/ blog/andre-trigueiro/post/2019/05/17/critica-deministro-contraria-parceiros-que-financiam-ofundo-amazonia.ghtml

Turollo, R., Jr., \& Fernandes, T. (2019, 24 de agosto). Governo federal cobra participação dos estados no combate ao fogo na Amazônia. Folha de S. Paulo. Recuperado de https://www1.folha.uol. com.br/ambiente/2019/08/governo-federal-cobraparticipacao-dos-estados-no-combate-ao-fogo-naamazonia.shtml

TV Cultura. (2019). Entrevista com Ministro do Meio Ambiente - Ricardo Salles.

Valor Online. (2019, 29 de outubro). Volume de óleo no Nordeste é semelhante ao vazamento no Golfo do México, diz presidente da Petrobras. G1. Recuperado de https://g1.globo.com/natureza/desastreambiental-petroleo-praias/noticia/2019/10/29/ volume-de-oleo-no-nordeste-e-semelhante-aovazamento-no-golfo-do-mexico-diz-presidente-dapetrobras.ghtml

Vick, M. (2019, 10 de abril). Qual o plano do governo para a concessão de parques nacionais? Nexo Jornal. Recuperado de https://www.nexojornal.com.br/ expresso/2019/04/10/Qual-o-plano-do-governopara-a-concessão-de-parques-nacionais

Vieira, R. (2019, 17 de agosto). Discurso antiambientalista de Bolsonaro preocupa empresários do agronegócio. O Globo. Recuperado de https://oglobo.globo.com/sociedade/discursoantiambientalista-de-bolsonaro-preocupaempresarios-do-agronegocio-23884165

Vilela, P. R. (2019, 17 de abril). Bolsonaro defende mineração e agropecuária em terras indígenas. Agência Brasil. Recuperado de http://agenciabrasil. ebc.com.br/politica/noticia/2019-04/bolsonarodefende-mineracao-e-agropecuaria-em-terrasindigenas

Viola, E., \& Franchini, M. (2017). Brazil and climate change: beyond the Amazon: Routledge.

Vivas, F. (2019, 18 de novembro). Maia cria CPI para investigar origem do óleo que atinge praias do Nordeste. G1. Recuperado de https://g1.globo. com/politica/noticia/2019/11/18/maia-cria-cpipara-investigar-origem-do-vazamento-de-oleo-queatinge-praias-do-nordeste.ghtml

Watkins, M., \& Rosegrant, S. (1996). Sources of power in coalition building. Negotiation journal, 12(1), 47-68.

Weible, C. M., Ingold, K., Nohrstedt, D., Henry, A. D., \& Jenkins-Smith, H. C. (2019). Sharpening advocacy coalitions. Policy Studies Journal, Early View. Recuperado de https://doi.org/10.1111/ psj. 12360

Weible, C. M., \& Heikkila, T. (2017). Policy conflict framework. Policy Sciences, 50(1), 23-40.

Weible, C. M.; \& Ingold, K. (2018). Why advocacy coalitions matter and practical insights about them. Policy \& politics, 46(2), 325-343.

Weible, C. M., Heikkila, T., Ingold, K., \& Fischer, M. (2016). Policy debates on hydraulic fracturing: comparing coalition politics in North America and Europe. New York, NY: Springer.

Weible, C. M., Heikkila, T., \& Pierce, J. (2018). Understanding rationales for collaboration in highintensity policy conflicts. Journal of Public Policy, $38(1), 1-25$.

Weible, C. M., \& Sabatier, P. A. (2009). Coalitions, science, and belief change: Comparing adversarial and collaborative policy subsystems. Policy Studies Journal, 37(2), 195-212.

Weible, C. M., Sabatier, P. A., \& McQueen, K. (2009). Themes and variations: Taking stock of the advocacy coalition framework. Policy Studies Journal, 37(1), 121-140. 


\section{Mauro Guilherme Maidana Capelari}

https://orcid.org/0000-0002-1259-9909

Ph.D. em Administração Pública e Políticas Públicas; Professor Adjunto do Centro de Desenvolvimento Sustentável da UnB. E-mail: capelari.unb@gmail.com

\section{Suely Mara Vaz Guimarães de Araújo}

https://orcid.org/0000-0003-2363-771X

Ph.D. em Ciência Política; Professora do Instituto Braziliense de Direito Público e do Instituto de Ciência Política da UnB. E-mail: suelymvg@gmail.com

\section{Paulo Carlos Du Pin Calmon}

https://orcid.org/0000-0001-6314-9564

Ph.D. em Ciência Política; Professor Associado do Instituto de Ciência Política da UnB.

E-mail: paulo.calmon@gmail.com

\section{Benilson Borinelli}

https://orcid.org/0000-0002-7256-7618

Ph.D. em Ciências Sociais; Professor Associado do Departamento de Administração da UEL.

E-mail: benilson@uel.br 